\title{
Systematic Consequences of Incumbency Advantage in the U.S. House Elections
}

\section{Citation}

King, Gary, and Andrew Gelman. 1991. Systematic consequences of incumbency advantage in the U.S. House elections. American Journal of Political Science 35(1): 110-138.

\section{Published Version}

doi: $10.2307 / 2111440$

\section{Permanent link}

http://nrs.harvard.edu/urn-3:HUL.InstRepos:4313307

\section{Terms of Use}

This article was downloaded from Harvard University's DASH repository, and is made available under the terms and conditions applicable to Other Posted Material, as set forth at http:// nrs.harvard.edu/urn-3:HUL.InstRepos:dash.current.terms-of-use\#LAA

\section{Share Your Story}

The Harvard community has made this article openly available.

Please share how this access benefits you. Submit a story.

\section{Accessibility}




\title{
Systemic Consequences of Incumbency Advantage in U.S. House Elections*
}

\author{
Gary King, Department of Government, Harvard University \\ Andrew Gelman, Department of Statistics, University of California, Berkeley
}

The dramatic increase in the electoral advantage of incumbency has sparked widespread interest among congressional researchers over the last 15 years. Although many scholars have studied the advantages of incumbency for incumbents, few have analyzed its effects on the underlying electoral system. We examine the influence of the incumbency advantage on two features of the electoral system in U.S. House elections: electoral responsiveness and partisan bias. Using a district-level seats-votes model of House elections, we are able to distinguish systemic changes from unique, election-specific variations. Our results confirm the significant drop in responsiveness, and an even steeper decline outside the South, over the past 40 years. Contrary to expectations, we find that increased incumbency advantage explains less than a third of this trend, indicating that some other unknown factor is responsible. Moreover, our analysis also reveals another dramatic pattern, largely overlooked in the congressional literature: in the 1940s and 1950s the electoral system was severely biased in favor of the Republican party. The system shifted incrementally from this severe Republican bias over the next several decades to a moderate Democratic bias by the mid-1980s. Interestingly, changes in incumbency advantage explain virtually all of this trend in partisan bias since the 1940s. By removing incumbency advantage and the existing configuration of incumbents and challengers analytically, our analysis reveals an underlying electoral system that remains consistently biased in favor of the Republican party. Thus, our results indicate that incumbency advantage affects the underlying electoral system, but contrary to the conventional wisdom, this changes the trend in partisan bias more than electoral responsiveness.

\section{Introduction}

The dramatic increase in the electoral advantage of incumbency has sparked widespread interest among Congressional researchers over the last 15 years. The original discovery by Erikson (1971) is often credited with a revival of interest in congressional elections. Indeed, incumbency is now viewed as "the central connective thread" running through the entire literature on Congress (Alford and Brady 1988, 1). Scholars have examined the trend in incumbency advantage through "sophomore surges" and "retirement slumps" (Erikson 1972; Cover and Mayhew 1977; Born 1979; Payne 1980; Alford and Brady 1988), "vanishing marginals" (Mayhew 1974), the average share of the vote won by incumbents (Alford and Hibbing 1981; Garand and Gross 1984), various survey instruments (Ferejohn 1977; Nelson, 1978-79; Mann and Wolfinger 1980; Krehbiel and

* Thanks to Neal Beck, Mo Fiorina, Bob Erikson, Don Rubin, and Charles Stewart for many helpful suggestions. This work is supported by National Science Foundation grant SES-89-09201 to Gary King and graduate fellowship to Andrew Gelman.

American Journal of Political Science, Vol. 35, No. 1, February 1991, Pp. 110-38

(C) 1991 by the University of Texas Press, P.O. Box 7819, Austin, TX 78713 
Wright 1983; Cain, Ferejohn, and Fiorina 1987), and more complicated estimators (Erikson 1971). ${ }^{1}$

Although many scholars have studied the electoral advantages of incumbency, few have analyzed its systemic consequences. In other words, we know a lot about what explains the outcome of individual congressional elections, but we know comparatively little about the underlying House electoral system and the more fundamental character of this part of U.S. representative democracy. This paucity of empirical research about these more basic issues does not indicate a lack of interest. For example, many scholars foresee incumbency advantage leading to a considerably less responsive system: Mayhew $(1974,314)$ refers to these trends in congressional elections as "the blunting of a blunt instrument." Fiorina $(1977,14)$ anticipates "the possibility of a Congress composed of professional office holders oblivious to the changing political sentiments of the country." Brady (1988) argues that major congressional policy change is now much less likely because incumbents are largely insulated from electoral swings.

Despite the gravity of these speculations, none have been the subject of sustained empirical analysis. We address this problem by analyzing the influence of incumbency advantage in the postwar U.S. House on two features of the underlying electoral system: electoral responsiveness and partisan bias, which we define formally in section 3 below. Those who study congressional elections have known for some time that incumbency advantage can diminish the responsiveness of congressional seats to changes in nationwide voter preferences (Tufte 1973). However, scholars have not explicitly estimated the effects of incumbency, as distinct from other aspects of U.S. politics, on electoral responsiveness. Indeed, although partisan bias holds a comparable theoretical status, most of the incumbency literature overlooks it entirely. Our results indicate that incumbency advantage has a determinate effect on the underlying electoral system, but contrary to the conventional wisdom, this effect has much more to do with partisan bias than electoral responsiveness.

Section 2 briefly introduces our unbiased measure of incumbency advantage and also describes the data we shall analyze. Section 3 reviews previous models of congressional elections. In section 4 we build on these previous efforts and develop a district-level model of the underlying electoral system that incorporates random variability among district-level vote swings. (The Appendix describes our estimation procedures for the model in section 4.) This model enables one to distinguish systematic changes in responsiveness and bias from chance electionspecific variations. Although our stochastic assumptions are more sophisticated

'Collie (1981) and Jacobson (1987) note that the incumbency advantage has not led to a drop in the probability of incumbent defeats from 1950 to 1984. This is disputed by Ansolabehere, Brady, and Fiorina (1988) and Bauer and Hibbing (1989). 
than previous models, our model is quite parsimonious, including only incumbency advantage, district effects, and a national swing.

Section 5 applies this model to postwar congressional election returns. Our results confirm a significant decline in responsiveness, and an even steeper decline outside the South, over the last 40 years. However, we find that increased incumbency advantage explains less than a third of this downward trend. The grave predictions of congressional scholars are therefore warranted, but the trend is not entirely due to the incumbency advantage. Furthermore, our analysis reveals another dramatic pattern in House elections that has been often overlooked in the congressional literature since Erikson's (1972) original finding: In the 1940s and 1950s, the electoral system was severely biased in favor of the Republican party, so much so that Republicans could reasonably expect to win about $58 \%$ of the seats in Congress with only half the nationwide vote. The gap between the parties' share of congressional seats was thus biased toward the Republicans by about 16 percentage points. However, the system gradually changed from this severe Republican bias over the next four decades to a moderate Democratic bias by the mid-1980s. ${ }^{2}$ Interestingly, we find that changes in incumbency advantage explain virtually all of this trend in partisan bias since the 1940s. By removing the incumbency advantage and the existing configuration of incumbents and challengers analytically, our analysis reveals an underlying electoral system that remains consistently biased in favor of the Republican party.

\section{Estimating the Incumbency Advantage}

We define the incumbency advantage as the average gain in the proportion of the district vote that the incumbent party receives if its incumbent candidate runs for reelection. To estimate this quantity, we use the estimator proposed and justified in Gelman and King (1990b). Denote $v_{1 \iota}$ and $v_{2 i}$ as the Democratic proportions of the two-party vote in district $i$ in elections 1 and 2, respectively. Let $I_{l}$ equal 1 if a Democratic incumbent runs for reelection, 0 if no incumbent runs, and -1 if a Republican incumbent is seeking reelection, in election 2 . In addition, $P_{1}$ is 1 if the Democrat wins election 1 and -1 if the Republican wins. We discard uncontested seats only for this part of the analysis. For a pair of election years, we base our measure of the incumbency effect $\psi$ on a linear regression of votes on incumbency status, controlling for previous votes and partisan swing:

$$
E\left(v_{2 \iota}\right)=\beta_{0}+\beta_{2} P_{\imath}+\beta_{1} v_{1 \imath}+\psi I_{\imath}
$$

where the least squares estimate of $\psi$ is our estimate of incumbency advantage. ${ }^{3}$

${ }^{2}$ Erikson (1972) is about the only scholar to see this pattern, and he did this without the luxury of the last 15 years of congressional elections. See also Tufte $(1973,550 ; 1974 b)$ and Ansolabehere, Brady, and Fiorina (1988).

${ }^{3}$ We actually estimate this equation by first transforming $v_{2 t}$ and $v_{1,}$ to the logit scale; for simplicity, we do not describe this in the text. This transformation does not substantively change the estimates. We do it so that our estimates will be compatible with the model in section 4 below. 
Figure 1. Electoral Swing with Small Incumbency Advantage (0.010)

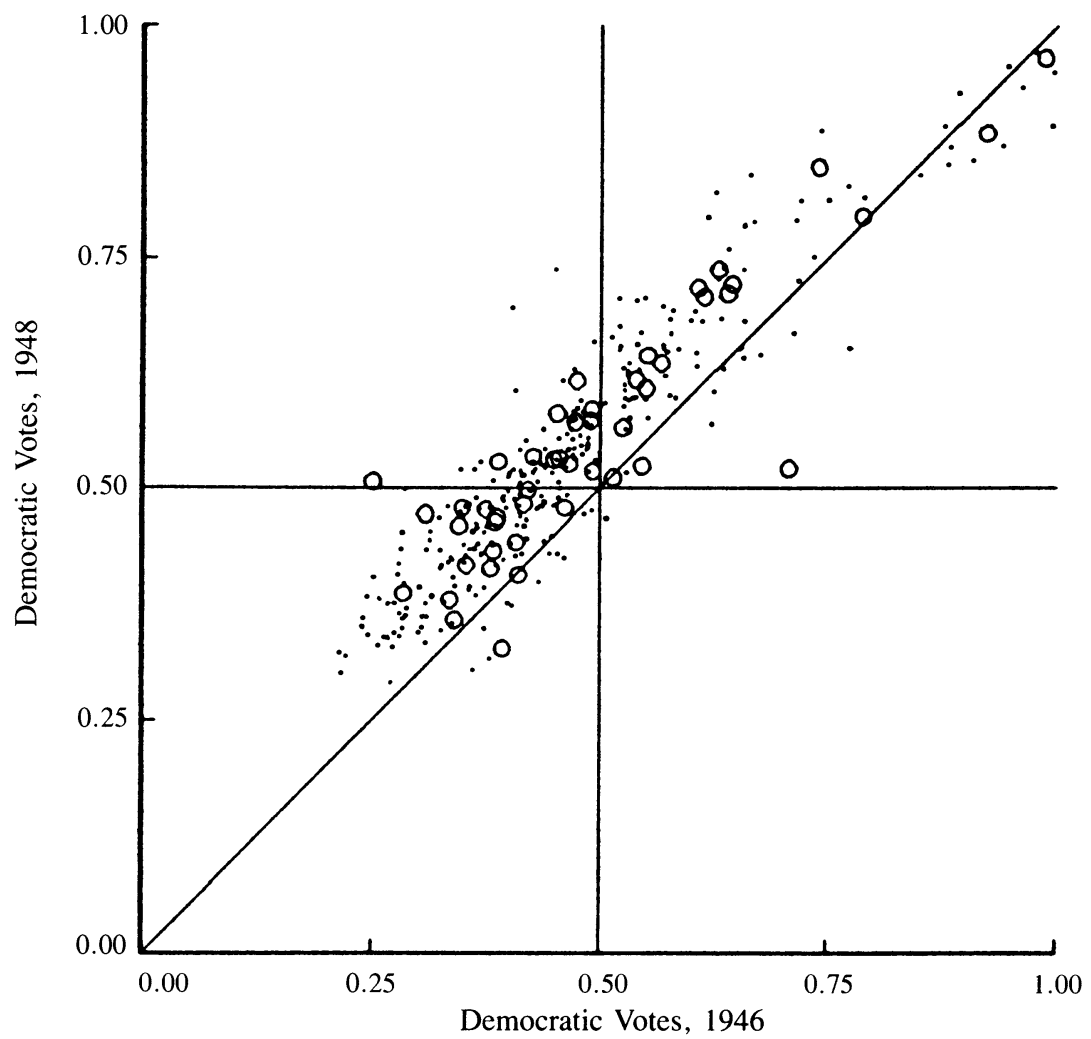

Dots are incumbents, and circles are open seats, in 1948.

Including $v_{1 \iota}$ considerably reduces the variance of the estimate of $\psi$ and eliminates a large source of possible bias. The party of the winner, $P_{i}$, allows the regression line of $v_{2 i}$ on $v_{1 i}$ and $I_{i}$ to be at different levels for Democrats and Republicans, with the slope of the line held constant. If $P_{\imath}$ were not included, $\psi$ would probably be underestimated. We could add a control variable to this equation for incumbency status at time 1 , but we find in practice that this has no appreciable effect on our estimate of $\psi$ and therefore omit it. ${ }^{4}$

Figures 1 and 2 give examples of the data we use to measure the incum-

${ }^{4}$ In Gelman and King (1990b), we demonstrate that sophomore surge, retirement slump, and all existing measures of incumbency advantage but this one are statistically biased; they also provide the necessary proofs and empirical evidence to support the use of this measure. Note also that whereas sophomore surge and retirement slump are based on only the approximately $10 \%$ of districts with sophomores or retirees, our measure is based on all contested districts (and has no variable indexing sophomore status or retirement). 
bency advantage (and its consequences, below) from the start (1946-48) and the end (1984-86) of our series. Both figures portray the electoral swing between two consecutive elections for all districts contested in both elections. The Democratic proportion of the two-party district vote is represented by a dot if an incumbent is running at time 2 and a circle if the seat is open at time 2 . Incumbency status at time 1 is not distinguished in these figures or our measure. Note first that the pattern of open seat and incumbent districts in Figure 1 are not noticeably different and that indeed incumbency advantage is about a single percentage point $(\hat{\psi}=0.010)$. In Figure 2 incumbent districts in 1986 still fall roughly parallel to the 45-degree line. However, open seats follow a distinctly different pattern, shifting much closer to 0.5 in 1986 than they were in 1984. Averaged over all districts, incumbency advantage from this figure is over 11 percentage

Figure 2. Electoral Swing with Large Incumbency Advantage (0.113)

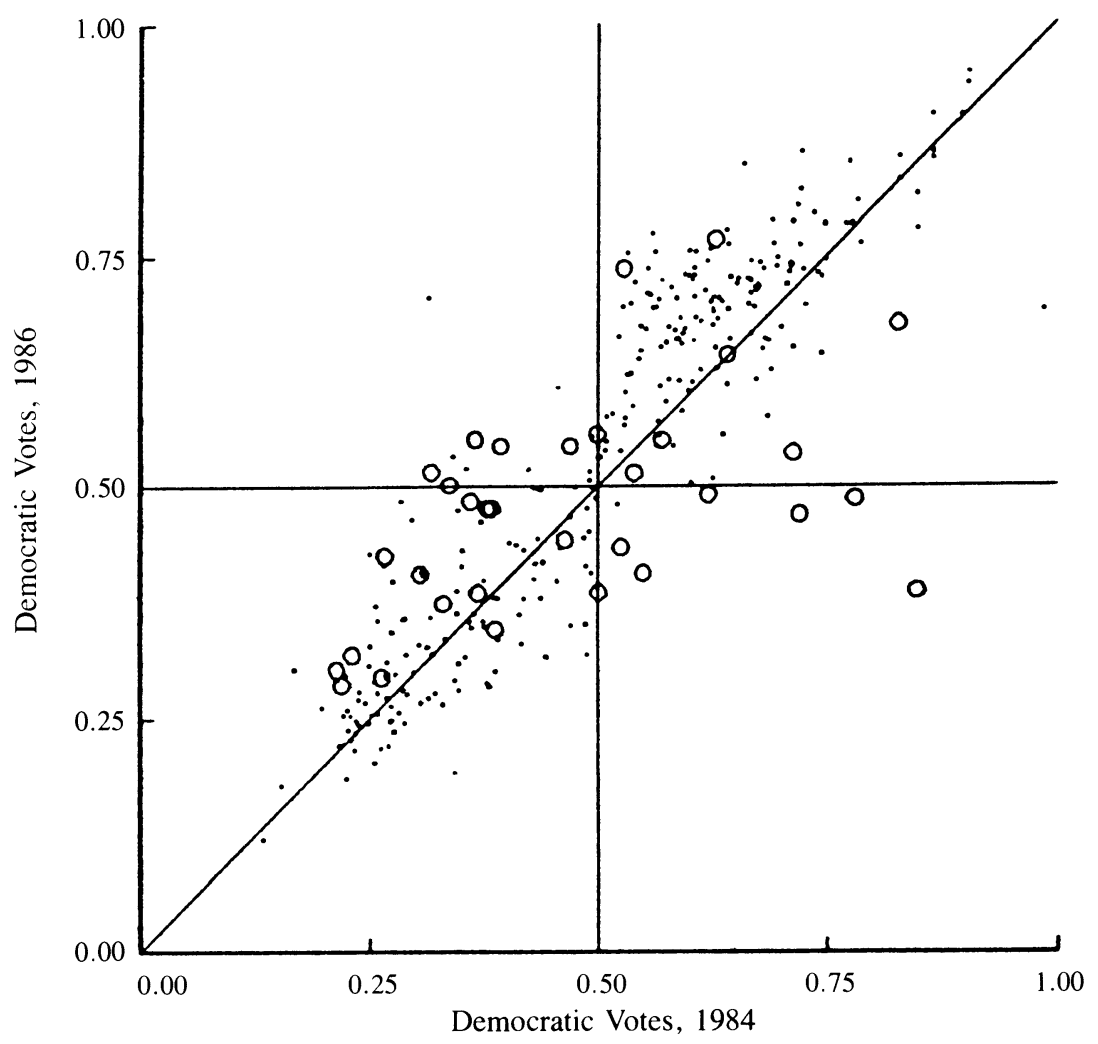

Dots are incumbents, and circles are open seats, in 1986. 
Figure 3. Estimates of Incumbency Advantage

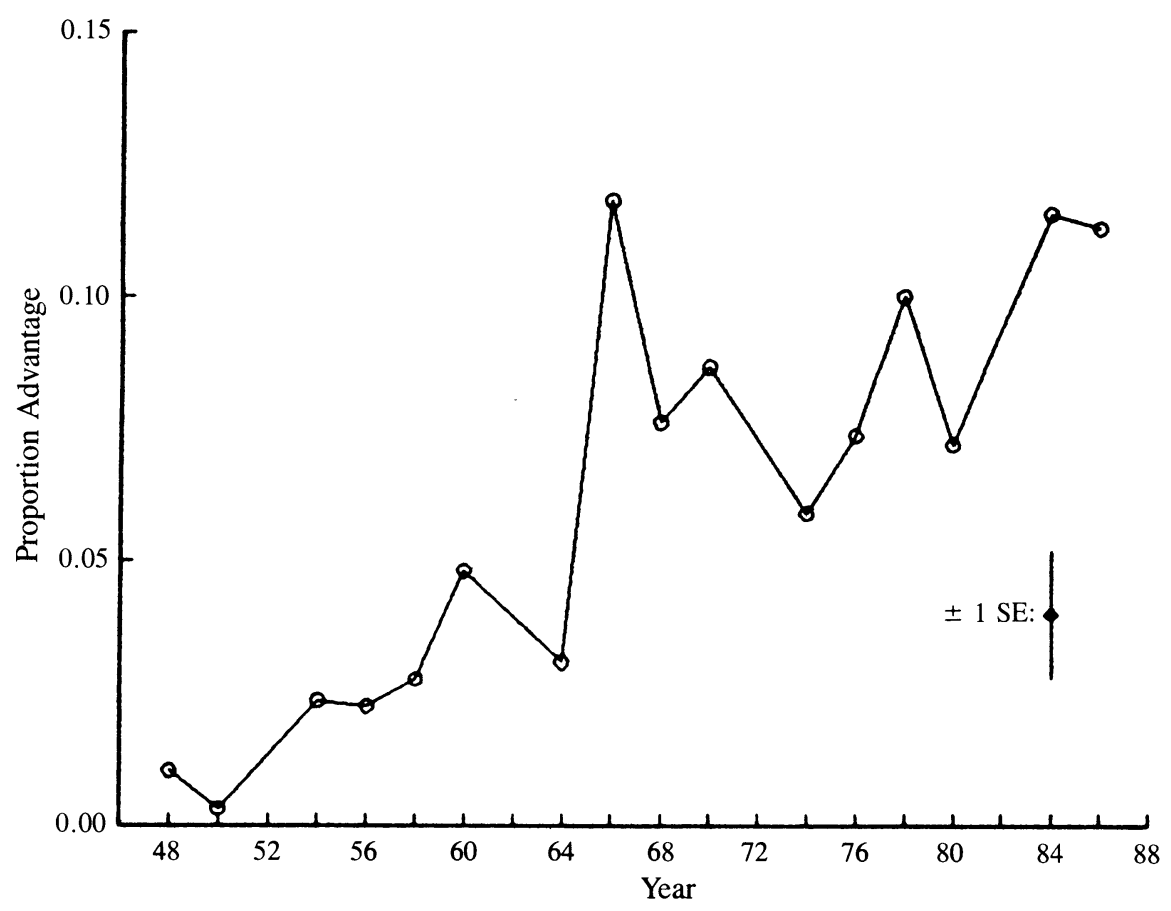

points $(\hat{\psi}=0.113)$. This also reveals the flaw in the sophomore surge measure, which is actually negative between 1946 and 1948, implying that incumbents were at a disadvantage. In 1984-86 sophomore surge is about half of our measure, and retirement slump is slightly lower, both just as predicted by our theoretical model presented in Gelman and King (1990b). ${ }^{5}$

Figure 3 graphs the incumbency advantage for all years from 1946-48 to 1984-86, except those that follow redistricting. The general pattern is a clear upward shift in the advantage of incumbency in House elections since World War II. The vertical bar in the lower right corner of the figure is the average size of plus and minus one standard error for each point in our estimation. Considering this uncertainty in estimation, it is easy to see that $\hat{\psi}$ is steadily increasing over the whole period. For the analyses that follow, we reduce estimation variabil-

${ }^{5}$ These figures are actually a rich summary of information about Congress. For example, the upper left and lower right quadrants of the figures represent those districts that changed parties. In Figure 1 about the same proportion of open seats and incumbents are in these portions of the graphs, whereas in Figure 2 open seats predominate. The figures also highlight Jacobson's (1987) finding that electoral swing in the later period has a larger variance. For further graphical analysis of these data, see King (1991). 
ity somewhat by using estimates from a linear regression fit to this figure: $\hat{\psi}=0.0156+0.0025$ (Year -1946 ), and the standard error on the slope is 0.0005 .6 We shall use these measures to evaluate the effect of incumbency advantage on partisan bias and electoral responsiveness.

\section{Previous Models of the Underlying Electoral System; Definitions of Electoral Responsiveness and Partisan Bias}

Previous work in this field has involved various theoretical constructs and related data summaries but extremely few statistical models. One early measure of responsiveness is the "swing ratio": the change in the proportion of legislative seats won by a party $(\bar{S})$, divided by the change in the nationwide average district vote $(\bar{V})$ received (Kendall and Stuart 1950). This concept was expanded to the "seats-votes curve," which is the fraction of the legislative seats won by a party, as a function of the average district vote (Quandt 1974; Niemi and Fett 1986). One can then calculate electoral responsiveness and partisan bias directly from this curve (Tufte 1973). Figure 4 presents two examples of seats-votes curves: one reflects de facto nationwide proportional representation, where $\bar{S}=\bar{V}$; the other represents a highly responsive electoral system near the middle of the votes scale (where elections are usually decided). Neither of these electoral systems is required by law in the United States, but either could emerge as the national aggregate of 435 single-member winner-take-all districts. Following Tufte (1973), Niemi and Deegan (1978), King and Browning (1987), and others, we consider these and other symmetric seats-votes curves to represent electoral systems that are fair to the political parties. The reason is that they treat both parties exactly the same way: if the Democrats are allocated a 0.75 fraction of the seats of 0.55 of the votes, this is fair only if the Republicans are allocated the same seat fraction if they receive the same 0.55 fraction of the votes. Thus, responsiveness of legislative seats to citizen votes can help distinguish the infinite variety of fair (i.e., symmetric) electoral systems. The more responsive the system, the larger the bonus beyond proportionality the majority party receives. We define partisan bias as a deviation from partisan symmetry.

Of course, a party's legislative representation does not depend only on the number of votes it receives; a deterministic seats-votes curve, as defined, cannot be more than a theoretical construct (Tufte 1973; Schrodt 1981). For this reason, we define the seats-votes curve in real electoral systems to be the expected value of $\bar{S}$ given $\bar{V}, E(\bar{S} \mid \bar{V})$, and we shall be interested in both this conditional expectation function and variability around it. We take the seats-votes curve and its associated variability to identify an electoral system. The two features of elec-

\footnotetext{
${ }^{6}$ This procedure is satisfactory, since the residual variance of this regression is comparable to our variance in estimation.
} 
Figure 4. Example Seats-Votes Curves

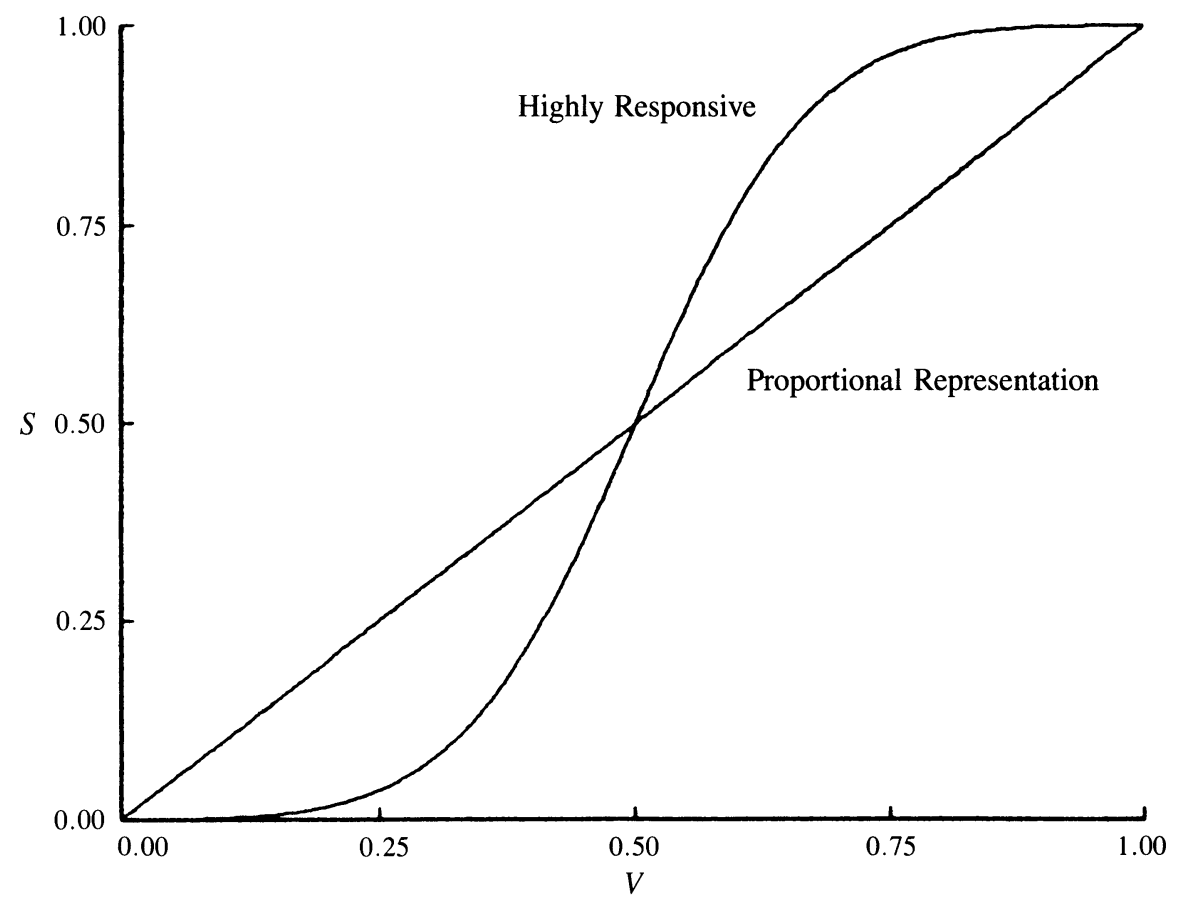

toral systems that we analyze in this paper, electoral responsiveness and partisan bias, can be defined more formally:

$$
\begin{aligned}
& \text { Responsiveness }(\bar{V})=\frac{d E(\bar{S} \mid \bar{V})}{d \bar{V}} \quad \text { and } \\
& \operatorname{Bias}(\bar{V})=E(\bar{S} \mid \bar{V})-[1-E(\bar{S} \mid \bar{V})]
\end{aligned}
$$

Note that responsiveness and bias are both functions of the nationwide average district vote. Responsiveness is then the change in the percentage of legislative seats for a single percentage point change in votes. Partisan bias is the difference between the expected proportion of seats won by the Democrats minus the expected proportion of seats won by the Republicans winning the same proportion of average district votes, $\bar{V}$. For a given degree of responsiveness, and value of nationwide votes, partisan bias is then the extent to which the existing gap in legislative seats between the parties is unfairly altered by the electoral system in favor of one party or the other. Negative values represent bias favoring the Republicans; positive values favor the Democrats.

Past researchers have empirically estimated bias and responsiveness in three 
ways. The most widely used method uses the nationwide Democratic fraction of seats won and the nationwide average district vote for a legislature in each of several consecutive elections. One can estimate the seats-votes curve by fitting a linear, logit (Tufte 1973), or bilogit (King and Browning 1987), regression to a scatterplot of these values. Summaries of responsiveness and bias can then be calculated from the estimated curve. This method uses very little data and consequently yields imprecise estimates. It also has the disadvantage of ignoring short-term systematic changes in the underlying electoral system, as might result from redistricting, for example, and is thus quite limited for present purposes.

The second method, dating back to Butler (1951; see also Gudgin and Taylor 1979; Niemi and Fett 1986), creates a "hypothetical" seats-votes curve from the district votes of a single statewide election, thus allowing one to track changes in the electoral system over time. This curve is drawn under the assumption of uniform partisan swing: as the nationwide average district vote $\bar{V}$ changes, the vote proportion in each district is assumed to change in exactly the same way. ${ }^{7}$

We formalize the model underlying uniform partisan swing as follows:

$V_{u t}=V_{\imath 0}+\delta_{t}$

where

$V_{t 0}$ is the observed Democratic proportion of the two-party vote in district $i$, and

$V_{u t}$ is a set of hypothetical election results defined by "national partisan swing" $\delta_{t}$.

The subscript $t$ refers to what we call "hypothetical time." Thus, the observed district-level electoral results are generated by setting $\delta_{t}=0$. Aggregating to the observed nationwide average district vote $\bar{V}_{t}=(1 / n) \sum_{l=1}^{n} V_{i t}$ and proportion of legislative seats $\bar{S}_{t}=(1 / n) \sum_{t=1}^{n} 1_{\left(V_{t}>05\right)}$ (where $1_{\left(V_{t}>05\right)}$ takes on the value 1 if $V_{t t}$ $>0.5$ and 0 otherwise) gives a single point on the seats-votes curve. One then adds and subtracts a range of values of national partisan swing $\delta_{t}$, each value generating a new set of hypothetical election results and a new point on the seatsvotes curve. The result is a curve like the one in Figure 5. Note that the unrealistic sharp jumps in the curve are due more to the method than to any inherent feature of the electoral system.

Uniform partisan swing can generate estimates of partisan bias and electoral responsiveness for each (real) election and can thus show short-term changes in

${ }^{7}$ In response to Backstrom, Robins, and Eller's (1978) proposal to use uniform partisan swing to assess partisan bias in political gerrymandering cases, even U.S. District Court and Supreme Court justices have debated this method (Bandemer v. Davis, 603 F. Supp. 1479, S.D. Ind., 1984; Davis v. Bandemer, 106 S.Ct. 2797, 1986). 
Figure 5. Uniform Partisan Swing, Congress, 1986

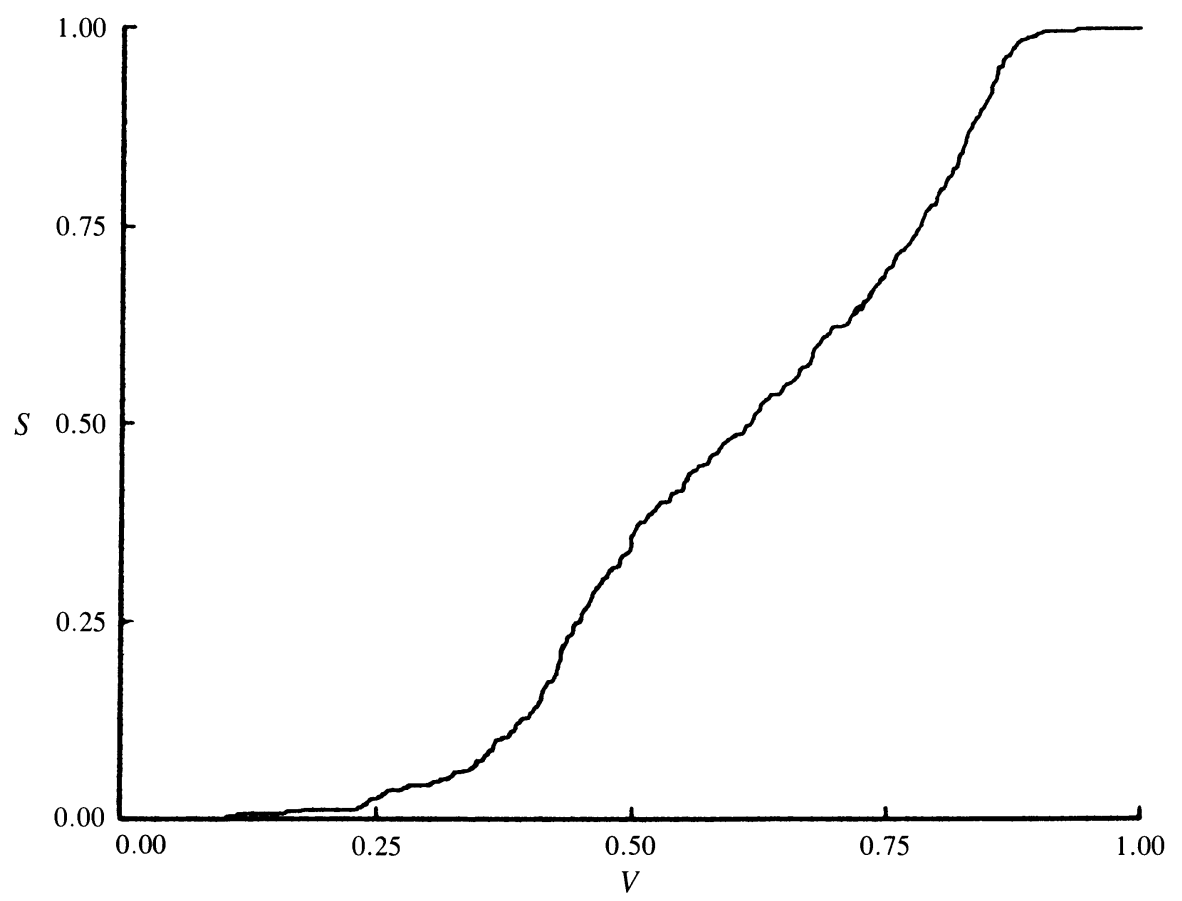

these features of the underlying electoral system. However, the method is both internally inconsistent and externally invalid. The uniform partisan swing method is internally inconsistent because when the same fraction $\delta_{t}$ is added to each district's vote total, districts that already have lopsided victories for a candidate will go over $100 \%$ or below $0 \%$ of the vote. Thus, although the uniform partisan swing assumption may work near the middle of the curve, it is obviously nonsensical at the extremes. Since much of the interest in bias and responsiveness is in the competitive region around $\bar{V}=0.5$, this inconsistency does not usually cause serious difficulties. However, for other substantive purposes, for more general models, and for logical consistency, some modification of this assumption is desirable.

The more serious external validity problem is that uniform partisan swing assumes that district votes from hypothetical elections held under essentially the same conditions all move in lockstep, swinging back and forth, in response to national electoral forces but without any random error or local factors to make them behave differently. Figures 1 and 2 show that elections in real districts do 
swing in an approximately uniform manner, but evidence for variability among districts is unmistakable. Ignoring this variation is the major weakness of uniform partisan swing, and it results in a model that is unable to distinguish true systematic changes in the underlying electoral system from mere random variability, produces standard error estimates of zero, and gives statistically inefficient estimates of bias and responsiveness.

A third model (King 1989b) explicitly includes random variability by assuming that the district vote proportions are identically distributed:

$$
V_{\imath} \sim f(v \mid \rho, \lambda)
$$

where $f$ is a specified two-parameter probability density defined on the interval 0 to 1 . From this district-level model of the electoral system, King (1989b) demonstrates how to derive a seats-votes curve and estimates of variability about it. This model makes minimal assumptions about the way districts move from election to election that allow considerably more flexibility than uniform partisan swing. Unfortunately, this model is far too unrestrictive in its assumptions about district votes, as can be shown by Figures 1 and 2 . Uniform partisan swing fails by predicting each of these graphs to be a straight line, with no scatter. King's (1989b) model makes the opposite assumption of independence of district votes between elections and would unnecessarily allow Figures 1 and 2 to look like scatterplots with zero correlation; this model also has the problem that it specifies a family of distributions that do not closely fit the observed Mayhew histogram data.

In the next section, we more reasonably assume that each district varies randomly around its own expected value, with some expected values being more Democratic than others. Since this alternative assumption incorporates more information about the electoral system, our estimates will be correspondingly more precise than those from this single distribution model.

\section{The Model}

In this section we present a new model of electoral systems that builds on the insights of previous approaches to estimation. Unlike Butler's (1951) uniform partisan swing, it explicitly models all sources of variability; unlike King's (1989b) single distribution approach, it incorporates more information about the way electoral systems actually operate.

We begin with observed votes, and we define $V_{t 0}$ as the Democratic proportion of the two-party vote in district $i$ in a single election. To avoid problems with vote proportions near 0 or 1 , we work with the logit of observed votes for districts with contested elections: $U_{l 0}=\operatorname{logit}\left(V_{l 0}\right)=\ln \left[V_{l 0} /\left(1-V_{l 0}\right)\right]$. (Recall that 0 on the logit scale is 0.5 on the votes scale; negative values of the logit indicate values of votes less than 0.5 ; and positive values are for votes larger than 0.5 ) 


\section{Uncontested Seats}

Models of congressional elections usually treat uncontested district elections in a special manner. For example, many scholars omit uncontested elections from all analyses. We do not take this approach because it creates unnecessary selection biases. Another method is to code uncontested wins as 1 onthe votes scale, but this probably overstates support for the winning candidate. Alternatively, one might impute a value for all uncontested districts (like 0.75 for Democrats, 0.25 for Republicans on the votes scale), but this overstates the certainty with which we know these values. Using the vote from the most recent contested election is problematic because it reduces our ability to observe changes in the electoral system, overestimates the certainty of these numbers, and may introduce bias for districts with long strings of uncontested elections. ${ }^{8}$

We solve this problem by defining the effective vote as the unobserved proportion of the two-party vote that a candidate would have won in his or her district, had the election been contested. For contested elections, the effective vote is merely the observed vote. Although our methods are different, this is conceptually the same definition as Erikson's (1972). For uncontested elections, we approximate uncertainty in the effective vote by the distribution of the vote proportions received by a party in a contested district, one election before an uncontested win by that party in that district. Figure 6 presents a "kernel density estimate" of these proportions, based on data from postwar congressional elections. Kernel density estimation is a smooth version of a histogram. Just like a histogram, the area under this curve in a range of vote proportions approximately equals the proportion of districts falling in this range. ${ }^{9}$

We summarize the information in Figure 6 by fitting it with a Normal density on the logit scale. That is, for each uncontested seat $i$, we model Democratic and Republican winners symmetrically:

$$
U_{\iota 0} \sim \begin{cases}\operatorname{Normal}\left(\mu_{u n}, \sigma_{u n}^{2}\right) & \text { for Democrats } \\ \operatorname{Normal}\left(-\mu_{u n}, \sigma_{u n}^{2}\right) & \text { for Republicans }\end{cases}
$$

Our data yield estimates (on the logit scale) of $\hat{\mu}_{u n}=0.95$ and $\hat{\sigma}_{u n}=0.58$. Thus, the effective votes in uncontested districts have a mean of roughly 0.72 proportion of the vote and a standard deviation of 0.14 . This procedure has significant advantages over other approaches in that it avoids selection bias and

${ }^{8}$ One might also use the vote within a district cast for a relatively minor statewide candidate like comptroller, but this may not be relevant to a district's legislative election. The method developed in the following paragraphs would enable one to see if this method of imputing votes is reasonable.

${ }^{9}$ The problem with histograms (in this case and most others) is that all variation within a bar is averaged and thus lost. Kernel density estimates smooth in a different way, preserving considerably more interesting substantive detail. See Silverman (1986). 
Figure 6. Density Estimate

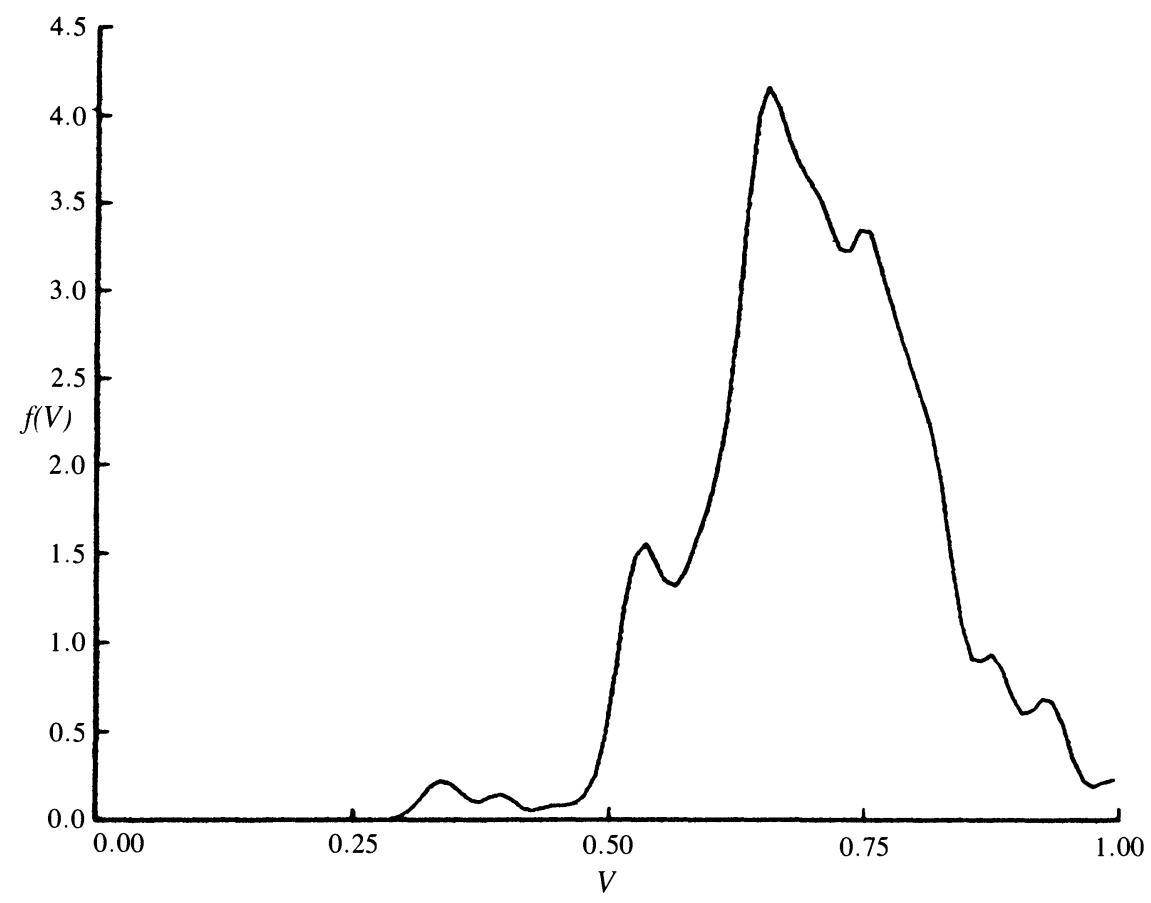

Density estimate of the proportion of the vote received by a party in a contested district election, immediately preceding an election in which that party was unopposed in that district, 1946-86.

incorporates all available information about the effective vote without overestimating our certainty about the outcome of a contested election that was never actually held.

\section{Statistical Model}

Having dealt with uncontested seats, we proceed to model district-level effective votes from a single election. This model extends uniform partisan swing by adding random error to equation 4 . In other words, we attempt to provide a realistic answer to the following question: What would happen to the effective district votes $v_{l}$ (or the effective logit votes $u_{\imath}$ ) in the event of a nationwide average vote swing of $\delta_{t}$ ? First, we assume that each district's effective vote on the logit scale is a random sample from a Normal distribution with a common variance $\sigma^{2}$ but with a district-specific expected value, $\alpha_{i t}$. This allows districts to retain distinct partisan dispositions and includes a reasonable assumption about variability (reflected in Figures 1 and 2). Second, we express each ex- 
pected value $\alpha_{t t}$ as the sum of two effects: a district effect $\gamma_{\imath}$ and a fixed parameter $\delta_{t}$ which we use to create hypothetical election results. This model is written formally as follows:

$$
\begin{aligned}
& U_{i t} \sim \operatorname{Normal}\left(\alpha_{t t}, \sigma^{2}\right) \\
& E\left(U_{i t}\right) \equiv \alpha_{t t}=\gamma_{t}+\delta_{t}
\end{aligned}
$$

where ${ }^{10}$

$\gamma_{i}$ is the predisposition of district $i$ to vote Democratic,

$\delta_{t}$ is a parameter representing nationwide partisan swing across hypothetical elections that we set to a range of different fixed values, and

the Normal distributions are independent over districts $i$ and hypothetical elections $t$.

The variance $\sigma^{2}$ determines the scope of the electoral system identified with the family of hypothetical elections. Setting $\sigma^{2}=0$, for example, causes the district effects to be exactly identified: $\gamma_{\iota}=U_{i 0}$. This unrealistic assumption of uniform partisan swing on the logit scale cannot hope to fit more than a single statewide election. Incorporating variability by estimating $\sigma^{2}$ also appears quite realistic since, as Figures 1 and 2 emphasize, districts do seem to move roughly in accord with our model.

\section{Adding Incumbency Effects}

We began with observed votes ( $U_{10}$ on the logit scale) and, controlling for uncontested seats, moved to effective votes. The expected value of effective votes is modeled as $E\left(U_{t 0}\right)=\gamma_{\imath}$ for a real election and $E\left(U_{t t}\right)=\gamma_{i}+\delta_{t}$ for hypothetical elections (each defined by hypothetical nationwide partisan swing $\delta_{t}$ ). We can now take the analysis one step deeper, to underlying partisan preferences by modeling the incumbency advantage. We define a district's partisan preference (denoted $\eta_{i}$ ) to be the effective vote in a contested election with no incumbent running. Thus, we decompose the expected effective district vote in the observed election:

$$
\gamma_{\imath}=\eta_{t}+\psi I_{i}+\delta_{t}
$$

where $\psi$ is an incumbency advantage as in section 2 (and not necessarily independent of $\gamma_{i}$ ):

$$
I_{\imath}=\left\{\begin{aligned}
1 & \text { for a Democratic incumbent } \\
0 & \text { for an open seat } \\
-1 & \text { for a Republican incumbent }
\end{aligned}\right.
$$

${ }^{10}$ The model in equation 6 is an equivalent, but more convenient, way of writing $U_{t}=\alpha_{t t}+$ $\varepsilon_{u}$ or $U_{u}=\gamma_{t}+\delta_{t}+\varepsilon_{t}$, where $\varepsilon_{u t}$ is a random disturbance term that follows a Normal distribution with mean 0 and variance $\sigma^{2}$. 
The expected district vote is then written as $E\left(U_{t 0}\right)=\eta_{t}+\psi I_{l}$ for a real election and $E\left(U_{t 0}\right)=\eta_{t}+\psi I_{t}+\delta_{t}$ for hypothetical elections. Expected partisan preferences are thus $\eta_{t}$ for the real electoral outcome or $\eta_{t}+\delta_{t}$ for the range of hypothetical elections. If the incumbent does not run, the partisan preference in a district equals the effective vote. We shall estimate the precise effect of incumbency on the underlying electoral system by comparing estimates of responsiveness and bias from this model based on partisan preferences with those based on effective votes.

\section{Creating the Seats-Votes Curve}

We apply this model to real data from a single election, labeled $t=0$, with observations $U_{10}, \ldots, U_{n 0}$, with the parameter $\delta_{0}$ set to zero. A family of "hypothetical election" results $U_{t}$ is then created by the model and applied to a range of nationwide partisan swing shifts $\delta_{t}$. For each of these shifts, we calculate the expected values of votes and seats $E(\bar{V})$ and $E(\bar{S})$ and the variance of our estimates. The seats-votes curve is formed by "connecting the dots" of these points $(\bar{V}, \bar{S})$.

The vector $\gamma=\left(\gamma_{1}, \ldots, \gamma_{n}\right)$, the district-level variance $\sigma^{2}$, the incumbency advantage $\psi$, and the uncontested vote parameters $\mu_{u n}$ and $\sigma_{u n}$, identify an "electoral system." We shall summarize this system by the seats-votes curve $E\left(\bar{S}_{t} \mid \bar{V}_{t}, U_{0}, \alpha_{t}\right)$, its variance $\operatorname{Var}\left(\bar{S}_{t} \mid \bar{V}_{t}, U_{0}, \alpha_{t}\right)$, and functions of these such as bias and responsiveness (equation (3)). Note that a large part of the realism of this model owes to explicitly modeling the variability about the seats-votes curve, summarized as $\operatorname{Var}\left(\bar{S}_{t} \mid \bar{V}_{t}, U_{0}, \alpha_{t}\right)$. This variability is a fundamental part of our model of the electoral system and is not the same as variability of estimation (which we introduce and estimate separately, below).

Finally, since the $n$ elements of $\gamma$ remain unknown, solely for purposes of estimation, we append to this model a random effects component by imagining $\gamma_{l}$, as samples from a mixture of three Normal distributions, identified by an eight-dimensional parameter $\theta=\left(\mu_{\jmath}, \rho_{J}^{2}-\sigma^{2}, \lambda_{j} ; j=1,2,3\right)$ of mean, variance, and mixture parameters with the constraint $\lambda_{1}+\lambda_{2}+\lambda_{3}=1 .{ }^{11}$ This random effects component explicitly incorporates the information in the wellknown "Mayhew histograms" of congressional district votes into our model.

\section{Empirical Results}

The seats-votes curve for House elections in 1986, estimated under the model in section 4, is the solid line in Figure 7. This line is computed on the

${ }^{11}$ Since the likelihood function is unbounded, standard maximum likelihood techniques fail (King 1989a). We therefore give the eight parameters a vague prior distribution and move to the Bayesian framework described in the Appendix. Changing the hyperparameter values to different reasonable values changes the estimates of $\theta$ only slightly, with negligible effects on our final estimates of bias and responsiveness. Details of the prior distribution appear in the Appendix. 
Figure 7. Seats-Votes Curve, U.S. House, 1986

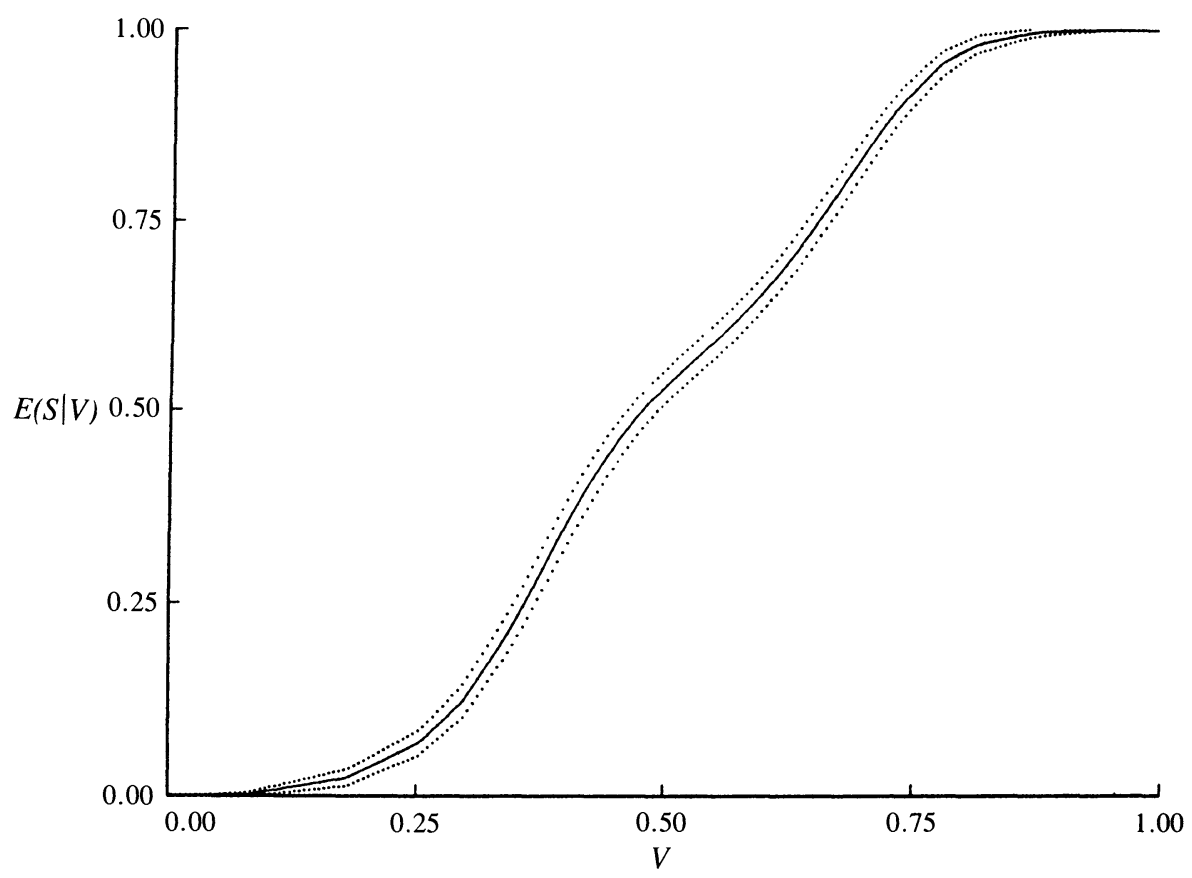

Dotted lines are \pm 1 standard error bounds.

basis of effective votes, without controlling for incumbency. The two dotted lines are plus and minus one standard error bounds on the seats-votes curve; note that the curve is quite precisely estimated. The electoral system's responsiveness is measured by the slope of the curve at particular values of $\bar{V}$. One can also assess partisan bias by comparing this curve to a symmetric one with the observed degree of responsiveness. Instead of interpreting this graph and the many others like it in this way, we summarize its relevant features. This is often done by evaluating the seats-votes curve at $\bar{V}_{t}=0.5$; we broaden this summary somewhat by using the average partisan bias and electoral responsiveness between $\bar{V}_{t}=$ 0.45 and $\bar{V}_{t}=0.55$, and the variances of these statistics. Many other summaries of our model are also possible.

We present these summaries and their corresponding standard errors based on effective votes for the entire U.S. House. We then control for the unique history and pattern of southern districts, as is common in this literature, by running the analysis for only nonsouthern districts. Finally, to remove the incumbency effect, we use the same model to generate estimates under the hypothetical situation where every seat is an open district. 
Figure 8 plots average partisan bias by average electoral responsiveness for all U.S. House elections from 1946 to 1986 . Each circle represents an election, and the time path of the underlying electoral system may be traced through responsiveness-bias space by following the lines from circle (election) to circle. (To retain clarity, only a few of the biennial congressional elections have been labeled.) The scale of each axis is easily interpretable: responsiveness is our estimate of the number of percentage points congressional seats would change for a one percentage point change in average nationwide votes. Thus, in 1946, if the nationwide average Democratic proportion of the two-party vote had increased from (say) $\bar{V}=0.53$ to $\bar{V}=0.54$, we would have expected the Democrats to increase their margin in the House by about 2.2 percentage points $(0.022$ fraction of the seats). Partisan bias is our estimate of how the two parties' seat fractions would differ due to inequities in the system near $\bar{V}=0.5$. Thus, in 1946, whatever the seat margin between the parties in the House, the gap was altered to favor the Republicans by about 15 percentage points solely due to inequities in the underlying electoral system. The cross in the lower left-hand corner of the figure is drawn to the average size of plus and minus one standard

Figure 8. U.S. House, 1946-86

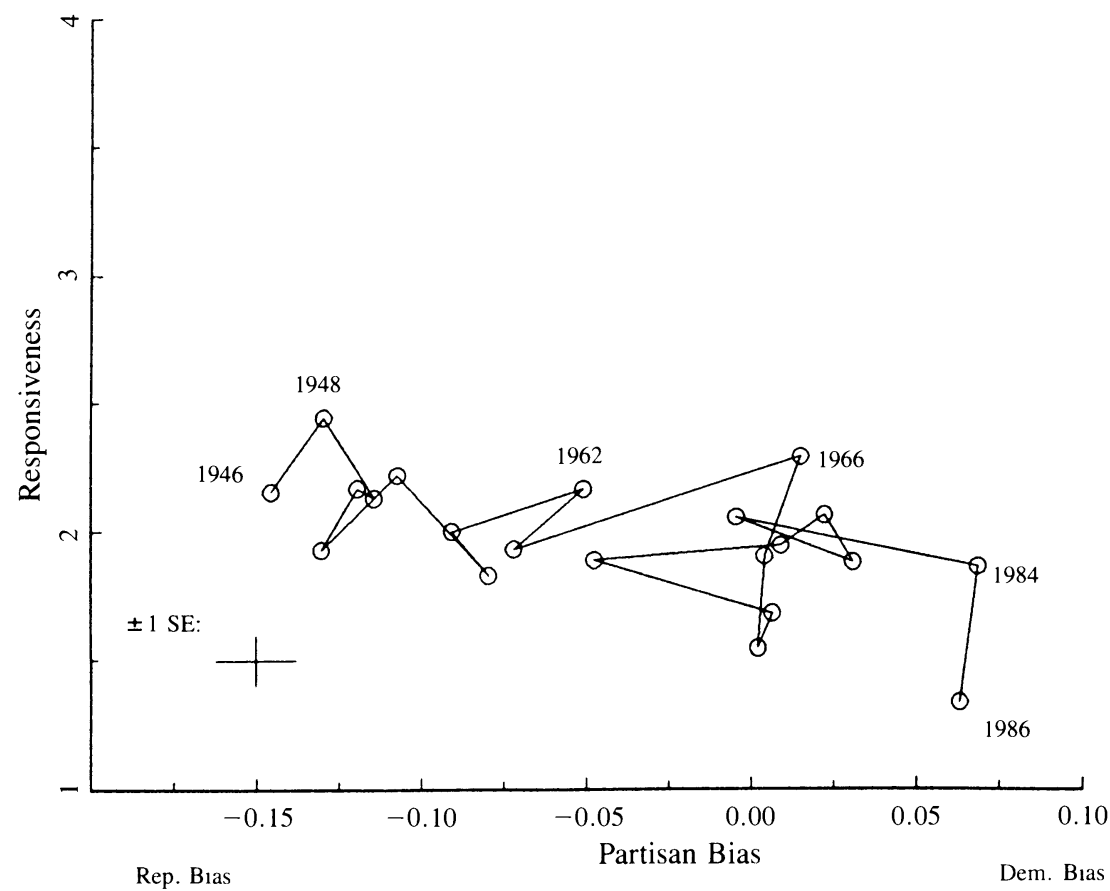


error vertically (for responsiveness) and horizontally (for partisan bias). One can therefore interpret each circle as estimated bias and responsiveness for a particular year and the cross as the size of the confidence interval around each point. Short-term changes smaller than these standard error bounds should be interpreted as probably unrelated to systematic changes in the underlying electoral system.

Two patterns are plainly evident in Figure 8. First, electoral responsiveness dropped by a full point-from about 2.3 in the late 1940 s to about 1.3 in 1986 . By comparing the long-term change to the standard error bounds, we can see that this steep decline in responsiveness is way outside what could be attributed to random chance alone. This general trend is consistent with the congressional elections literature. Our analysis has the virtue of providing considerably more precise estimates and demonstrates that these trends in responsiveness reflect systematic changes in the underlying electoral system rather than merely variability in estimation.

While putting considerable resources into studying this decline in responsiveness, congressional scholars have all but missed an even more dramatic trend in partisan bias: in 1946 the House was biased by as much as 15 percentage points in favor of the Republican party, but over the course of the next four decades, bias moved steadily in favor of the Democrats. From 1946 to the late 1960 s, this Republican bias was gradually eroded. From the 1960s to the early 1980 s, the electoral system seemed stalled near zero bias. But then the same trend picked up again so that by 1986 the underlying electoral system was biased toward Democratic candidates by slightly more than six percentage points.

These patterns of bias and responsiveness are exaggerated by dropping the southern states from the analysis. Figure 9 presents these results. The range of partisan bias increases slightly, but the range of responsiveness more than doubles. From the beginning to the end of the period, responsiveness dropped more than two points, from about 3.4 to 1.3. The difference in the responsiveness between the two figures is particularly dramatic at the start of the series. However, by the mid-1960s, responsiveness in the non-South (in Figure 9) and the entire country (in Figure 8) track quite closely.

Finally, we turn from effective votes in the non-South to underlying partisan preferences. We derive these partisan preferences with our model by estimating the seats-votes curve, and corresponding summaries of bias and responsiveness, in the hypothetical situation where incumbents do not run. For each election we assume everything remains the same as before up to the election we are studying, but in this election no incumbents run. Because incumbency provides an electoral advantage, as we show in section 2 , responsiveness is bound to increase if every congressional district is an open seat. (Conversely, with a large incumbency advantage, it takes a larger vote swing to unseat incumbents, and respon- 
Figure 9. U.S. House, Non-South, 1946-86

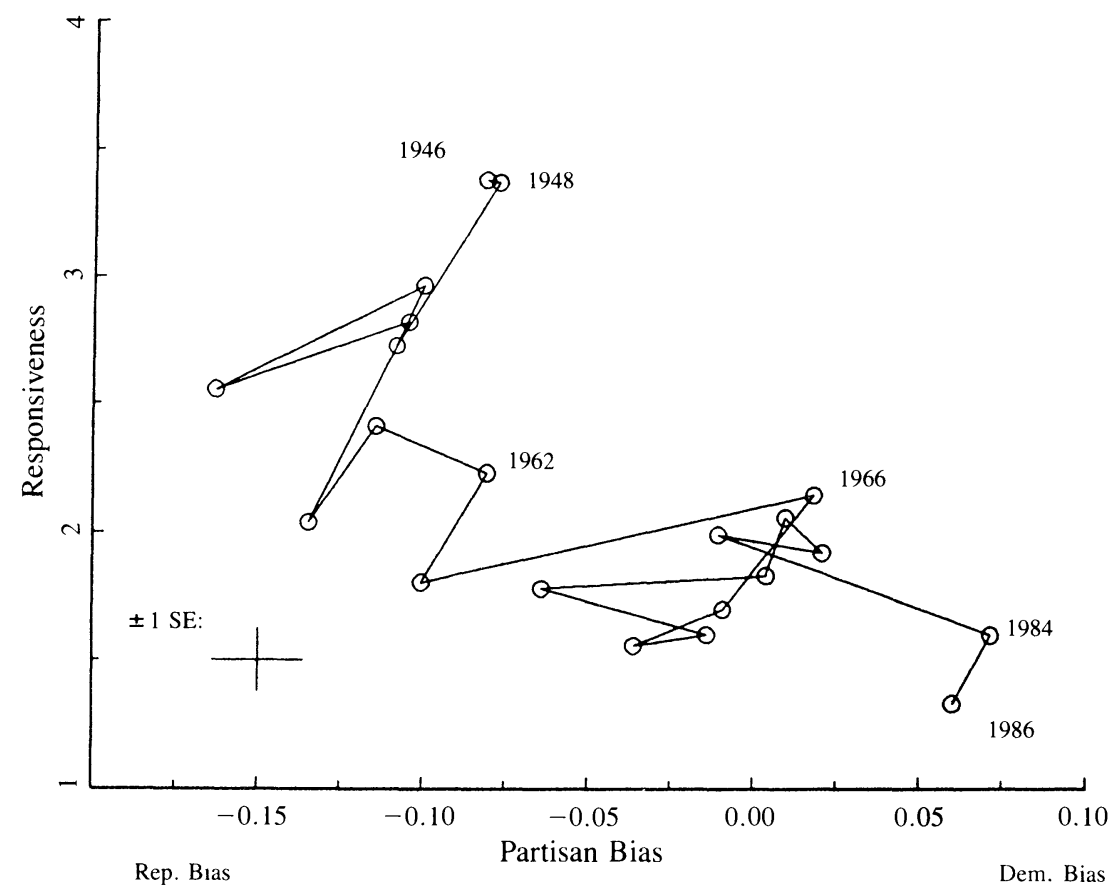

siveness is low.) However, the extent of this effect, and the effects of the incumbency advantage on trends in responsiveness and bias observed in Figure 9 are unknowable without moving to the data.

Thus, we turn to Figure 10, the bias-responsiveness plot for the non-South with the incumbency effect removed. As expected, the entire figure has shifted upward (the vertical axis now ranges from 2 to 5 instead of 1 to 4 ). The shift is roughly an additional $1.3 \%$ seat swing for every $1 \%$ vote swing. Removing the incumbency advantage explains the most dramatic change in responsiveness from Figure 9, that from 1946 to 1964 , and also seems to explain most of the trends before and after the late 1960s. However, the effects of incumbency advantage do not appear to account for the sharp drop in responsiveness between the two periods and overall account for less than a third of the postwar decline in responsiveness. ${ }^{12}$

This graph, like the last, reveals a change in the pattern of bias: removing the incumbency advantage wipes out nearly all of the dramatic trend toward

${ }^{12}$ This figure is arrived at by regressing responsiveness on election year for each figure and observing the drop in the slope. 
Figure 10. U.S. House, Non-South, Incumbency Effect Removed, 1946-86

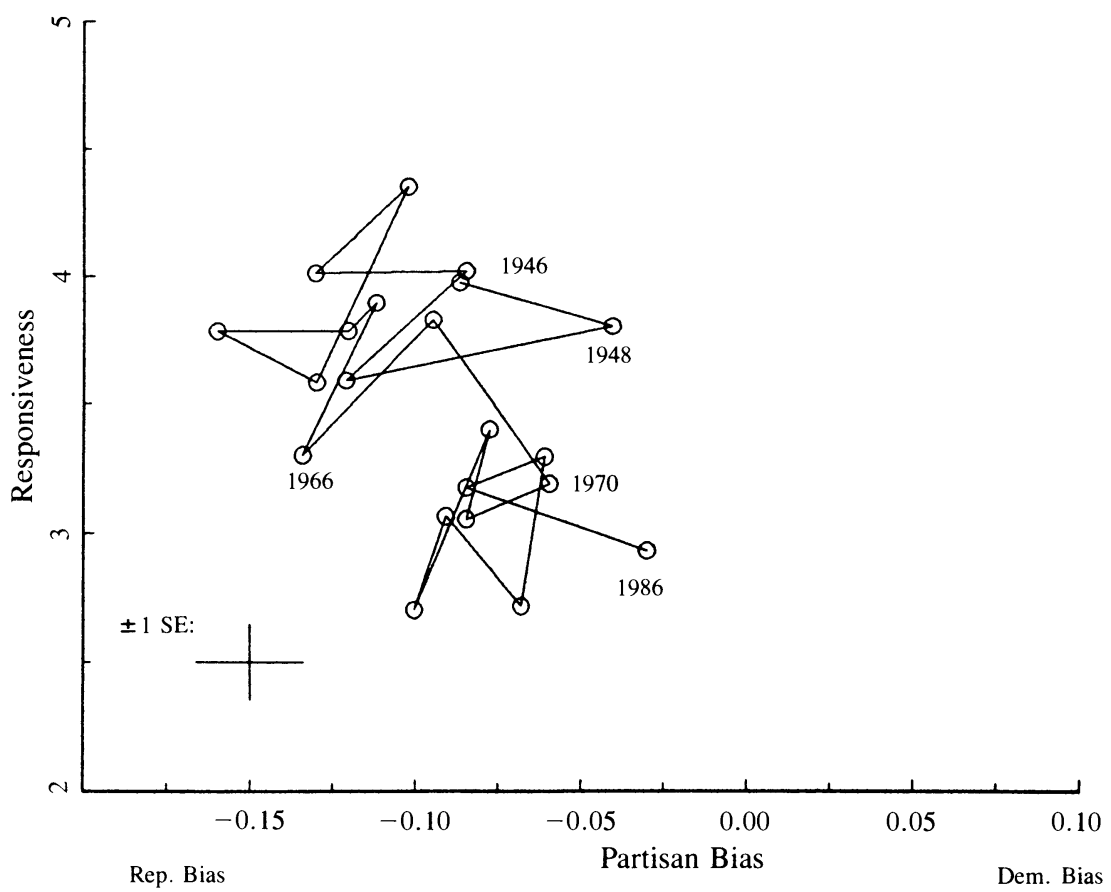

Democratic bias since the 1940s. ${ }^{13}$ Whereas the overall electoral system in the nonsouthern states moved from severe Republican bias to moderate Democratic bias, the deeper patterns beneath the configuration of incumbents and their electoral advantages reveal an electoral system that has remained severely biased toward the Republican party for all elections in the last four decades. Only the particular existing pattern of incumbents keeps the system biased in favor of the Democrats.

\section{Discussion and Conclusions}

This paper bears on much of the research in congressional elections over the last two decades. We built a district-level model of congressional voting that separates systematic changes in the underlying electoral system from mere chance events not expected to persist between elections. With this model, we calculated estimates and standard errors of partisan bias and electoral responsiveness for every postwar House election. The nonsouthern districts were found 9 to 10 .

${ }^{13}$ The slope from the regression of partisan bias on election year drops about $80 \%$ from Figures 
to differ from the country as a whole in the 1940s and 1950s, with the difference declining to near zero by 1966 . We found that electoral responsiveness declined substantially since 1946, and even more dramatically outside the South. Also as expected, incumbency largely explains the aggregate level of responsiveness. However, we also found that less than a third of the trend in responsiveness could be accounted for by trends in incumbency advantage-considerably less than that implicitly hypothesized in the literature. A plausible explanation for the rest of the decline in responsiveness is the increasing resources and desirability of elective offices in the postwar period. This "electoral institutionalization" has many consequences, including the localization of congressional elections, which leads to lower responsiveness.

At the same time, partisan bias has followed an equally dramatic, and often overlooked, trend. Before and after removing the South, bias heavily favored the Republicans in the 1940 s and moved steadily toward a moderate Democratic bias by 1986 . We also found that the incumbency advantage explains almost all of the trend in bias in this period. In the 1940s the electoral system was biased in the Republicans' favor because the pattern of uncontested and landslide district elections caused the Democrats to "waste" more votes. The pattern of contestedness has equalized in recent decades, and the Democrats now have a bias in their favor. However, the incumbency advantage now favors the Democrats (because Democratic incumbents outnumber Republican incumbents), and removing this advantage, as in Figure 10, shows an underlying system still biased in favor of the Republicans.

Incumbency thus has a powerful influence on the political system, but not entirely the influence that was previously thought. Perhaps most important, then, this paper gives a more fundamental justification to the large body of congressional elections research devoted to describing and explaining the increased incumbency advantage: not only is this advantage of concern to members of Congress and their challengers, but it affects the responsiveness of the entire system to citizen votes.

One factor that seems unlikely to account for all of these trends is redistricting. The reason for this is the lack of any dramatic single-year change in responsiveness, particularly during the redistricting years 1970-72 and 1980-82. Although redistricting may have had large effects in particular states and may account for some of the election-to-election variability in these figures, it seems an unlikely candidate for directly explaining long-term systematic trends across the country. Of course, inferring from these aggregate data to individual level causal explanations can only be speculative (Tufte 1974a, 212). Sorting out the precise causes, and even more microlevel causal mechanisms, should remain high on the congressional research agenda.

Another topic for future research is explaining trends in partisan bias. Although we explain the vast majority of these trends in this paper with a single 
variable - incumbency - we still need to explain exactly how incumbency has this effect. One advantage of our measures of partisan bias, electoral responsiveness, and incumbency advantage is that they do not track with changes in support for the Democrats and Republicans, but the particular configuration of incumbents and challengers around the nation certainly depends on their pattern of partisan support. The explanation of this trend in bias seems to be that the incumbency advantage happened to begin its dramatic increase at a time (the 1940s) when Democrats held a majority of House seats. The advantage therefore began to benefit the Democrats when the electoral system happened to be biased in favor of the Republicans. As the incumbency advantage grew stronger, Democrats won more close elections and turned a severe Republican bias into a moderate Democratic bias.

Furthermore, we know that a large part of legislative redistricting, in both theory and practice, is concerned with incumbent protection (Mayhew 1971; Tufte 1973; Cain 1985; Owen and Grofman 1988). Although redistricting seems an unlikely direct explanation for long-term systematic changes in the underlying electoral system, perhaps redistricting operates on the electoral system primarily through the incumbency advantage.

\section{Manuscript submitted 11 May 1989 \\ Final manuscript received 21 March 1990}

\section{APPENDIX}

In this Appendix we elaborate and extend the estimator originally developed by Gelman and King (1990a) in order to estimate the model in section 4. Our goal is to estimate the seats-votes curves, from which we derive bias and responsiveness summaries. The expected values of seats and votes depend on the expected logit vote proportions $\gamma_{l}$, from each district, and on the variance $\sigma^{2}$ between hypothetical election results within districts. We estimate this model in four steps, to be described below:

A. Preliminary estimation. We estimate $\sigma^{2}$ from election-to-election variance within districts, using data from all the postwar elections.

B. Estimation for a single election. We estimate the parameters $\gamma_{1}$ for each election year separately. This allows us to summarize the electoral system for each postwar election and to track changes over time. To do the estimation, we use Bayesian methods: conditioning on the data $u_{0}=$ $\left(u_{00} ; \quad i=1, \ldots, n\right)$ from a single election to sample from the posterior distribution $P\left(\gamma \mid u_{0}\right)$ of the vector $\gamma$. We use the $\sigma^{2}$ estimated previously.

C. The seats-votes curve. We average over $P\left(\gamma \mid u_{0}\right)$ to estimate the posterior seats-votes curve:

$$
E\left(S_{t} \mid V_{t}, u_{0}\right)
$$

(We allow $V_{t}$ to range from 0 to 1 by allowing $\delta_{t}$ to range from $-\infty$ to $\infty$ on the logit scale.) We also estimate the expected variance of results across hypothetical elections:

$$
E\left(\operatorname{Var}\left(S_{t} \mid V_{t}, u_{0}, \gamma\right)\right)
$$


and our uncertainty in the seats-votes curve due to our uncertainty in $\gamma$ :

$\operatorname{Var}\left(E\left(S_{t} \mid V_{t}, u_{0}, \gamma\right)\right)$

D. Summaries. From the estimated seats-votes curve, equation (9), and related conditional expectations, we estimate bias and responsiveness summaries of the definitions in equation (2):

(average responsiveness between $V=0.45$ and $V=0.55$ )

$=\frac{1}{0.55-0.45}[E(S \mid V=0.55)-E(S \mid V=0.45)]$

(average bias between $V=0.45$ and $V=0.55$ )

$$
=\frac{1}{0.55-0.45} \int_{045}^{055}(E(S \mid V)-[1-E(S \mid 1-V)]) d V
$$

We calculate the posterior mean and variance of these summaries.

\section{Election-to-Election Variability}

Our linear model creates hypothetical district election results $u_{u t}$ from the district effects $\gamma_{t}$ by adding a constant shift $\delta_{t}$ to the mean in every district. From here, we add the variability in equation (7); this "unexplained" variance $\sigma^{2}$ determines the scope of the electoral system identified with the family of hypothetical elections. Setting $\sigma^{2}=0$, for example, causes the district effects to be exactly identified: $\gamma_{1}=u_{i 0}$. This assumption of "uniform partisan swing on the logit scale" cannot hope to fit more than a single nationwide election.

We estimate $\sigma^{2}$ from a model of the variances in real district-level election results, across time. We use the following conceptual model:

(variance between two elections, $Y$ years apart)

$=$ (variance due to randomness in individual elections)

+ (variance due to changes in the underlying electoral system)

In this framework the first term on the right-hand side of this equality is $2 \sigma^{2}$; we imagine the second quantity to be roughly proportional to $Y$. Note that from equation (7), the difference $u_{t_{1}}-u_{t t_{2}}$ has variance $2 \sigma^{2}$ if their two Normal distributions are independent.

For each pair of election years $t_{1}$ and $t_{2}$, we calculate the sample variance of the change in district vote, for districts contested in both elections:

$$
s_{i_{1} / 2}^{2}=\left(1 / n_{t_{1} / 2}\right) \sum_{1}\left[u_{i_{1}}-u_{t_{2}}-\left(\bar{u}_{t_{1}}-\bar{u}_{i_{2}}\right)\right]^{2}
$$

where $n_{t_{1} / 2}$ is the number of districts contested in both elections $t_{1}$ and $t_{2}$. We calculate this quantity for all elections years $\left(t_{1}, t_{2}\right), t_{1}<t_{2}$, between 1946 to 1986, but do not track district votes across redistricting. We then fit a linear regression of the values $s_{t_{1^{\prime} 2}}^{2}$, as a function of the time differences $\left(t_{2}-t_{1}\right)$ and the year $\left(t_{1}+t_{2}\right) / 2$. Our estimate of $2 \sigma^{2}$ is just the estimate of the constant term in this regression plus a linear trend over time.

\section{The Distribution of District Effects $\gamma_{t}$}

We need to estimate the vector $\gamma$ of district effects and our uncertainty in it. Embedding $\gamma$ in a lower-dimensional probabilistic model allows us to estimate these $n$ district effects from the $n$ data points $u_{t 0}$. To do this we impose a set of probabilistic assumptions about $\gamma$ in the form of a prior distribution. We parameterize this distribution based on our knowledge from the literature on "Mayhew histograms" of constituency vote proportions. 
Table A.1. Specified Hyperparameter Values for the Prior Distribution on $\theta$

\begin{tabular}{cccl}
\hline \hline Parameter & $j=1$ & $j=2$ & $j=3$ \\
\hline$\mu_{\mu_{J}}$ & -0.4 & 0.4 & 0 \\
$\sigma_{\mu_{J}}$ & 0.4 & 0.4 & 3 \\
$\alpha_{\rho_{J}}$ & 4 & 4 & 4 \\
$\beta_{\rho_{J}}$ & 0.16 & 0.16 & 0.64 \\
$\alpha_{\lambda_{j}}$ & 19 & 19 & 4 \\
\hline
\end{tabular}

We consider the district effects to be drawn from a mixture of three Normal distributions, identified by an eight-dimensional parameter $\theta=\left(\mu_{\jmath}, \rho_{\jmath}^{2}-\sigma^{2}, \lambda_{\jmath} ; j=1,2,3\right)$ of means, variances, and mixture proportions, with the constraint $\lambda_{1}+\lambda_{2}+\lambda_{3}=1$. These three humps are meant to fit a Mayhew histogram of district vote proportions $v_{\imath}$ in a single election. Such histograms typically have an area of Republican strength (a set of districts with $v_{\imath}<0.5$ ), an area of Democratic strength $\left(v_{t}>0.5\right)$, and scattered districts that fit no clear pattern.

The method of maximum likelihood is inadequate to estimate these eight parameters, since the likelihood function is unbounded. We therefore give the eight parameters a prior distribution and move to Bayesian estimation. It is mathematically convenient, and substantively sufficient, to choose a family conjugate to an $N\left(\gamma_{t}, \sigma^{2}\right)$ distribution:

$$
\begin{gathered}
\mu_{\jmath} \sim N\left(\mu_{\mu_{j}}, \sigma_{\mu_{j}}^{2}\right), \quad j=1,2,3 \\
\rho_{J}^{-2} \sim \Gamma\left(\frac{1}{2} \alpha_{\rho_{J}}, \frac{1}{2} \beta_{\rho_{J}}\right), \quad j=1,2,3 \\
\left(\lambda_{1}, \lambda_{2}, \lambda_{3}\right) \sim \operatorname{Dirichlet}\left(a_{\lambda_{1}}, a_{\lambda_{2}}, a_{\lambda_{3}}\right)
\end{gathered}
$$

Table A.1 specifies these distributions; we have chosen these hyperparameters based on our substantive knowledge, and from inspection of Mayhew histograms of Congress. When possible, we approximate to make prior assumptions about $\theta$ vague rather than overly restrictive. Note that the hyperparameters probabilistically determine the set of possible values of $\theta$, which in turn determines the distribution of expected logit vote proportions $\gamma_{i}$. We do not specify $\theta$; rather, we shall estimate it from the data. The specific hyperparameters of Table A.1 allow the centers of the two main humps (representing the Republican and Democratic districts) to fall with highest probability between $v_{t}=$ 0.3 and 0.7 , with widths of about 0.2 . We allow the third hump to be more spread out and smaller, with its center determined freely by the data. The special cases of one, two, and three humps are modeled in this specification, allowing us to fit wide varieties of observed electoral results. Finally, we truncate this distribution so that $\left(\rho_{j}^{2}-\sigma^{2}\right) \geqslant 0$ for $j=1,2,3$.

\section{Bayesian Estimation for a Single Election}

We summarize posterior distributions by sampling from, in the following order:

1. $P\left(\theta \mid u_{0}\right)$

2. $P\left(\gamma \mid \theta, u_{0}\right)$

3. $P\left(u_{t} \mid \delta_{t}, \gamma, \theta, u_{0}\right)=P\left(u_{t} \mid \delta_{t}, \gamma\right)$

Together, these steps amount to sampling from the desired posterior distribution of election results. (All these distributions are of course conditional on the parameter $\sigma^{2}$ estimated above.) 


\section{Averaging over Uncertainty in $\theta$}

The posterior density $P\left(\theta \mid u_{0}\right)$ is cumbersome because of the Normal-mixture terms in the likelihood. Direct sampling or numerical integration over this eight-dimensional distribution seems impossible. With a Normal likelihood, however, simulation of $\theta$ would be easy. We exploit this possibility through the data augmentation algorithm of Tanner and Wong (1987).

First, we decompose the Normal-mixture through a matrix of unobserved indicator variables $\tau$ $=\left(\tau_{l} ; i=1, \ldots, n ; j=1,2,3\right)$. The likelihood $P\left(u_{0} \mid \theta\right)$ can then be factored into independent multinomial distributions for the indicators:

$$
\left(\tau_{11}, \tau_{12}, \tau_{13} \mid \theta\right) \sim \text { Multinomial }\left(\lambda_{1}, \lambda_{2}, \lambda_{3} ; 1\right), \text { for } i=1, \ldots, n,
$$

and a Normal distribution for the data, conditional on these indicators:

$$
\left(u_{t 0} \mid \tau_{\imath \jmath}=1, \theta\right) \sim N\left(\mu_{\jmath}, \sigma_{j}^{2}\right)
$$

Next, we sample from $P\left(\theta \mid u_{0}\right)$, in two steps, using the intermediate variable $\tau$.

1. Sample from $P\left(\tau \mid u_{0}\right)$, and

2. Sample from $P\left(\theta \mid \tau, u_{0}\right)$

Step 2, using Bayes's theorem with our conjugate prior distributions, equation (13), is straightforward:

$$
\begin{aligned}
\left(\rho_{J}^{-2} \mid \tau, u_{0}\right) & \sim \Gamma\left(\frac{1}{2}\left(\alpha_{\rho_{\jmath}}+n_{\jmath}\right), \frac{1}{2}\left(\beta_{\rho_{J}}+\mathrm{SS}_{\jmath}\right)\right), j=1,2,3, \\
\left(\mu_{J} \mid \rho_{J}^{2}, \tau, u_{0}\right) & \sim N\left(\mu_{J}^{*}, \rho_{J}^{*}\right), j=1,2,3, \\
\left(\lambda_{1}, \lambda_{2}, \lambda_{3} \mid \tau, u_{0}\right) & \sim \text { Dirichlet }\left(a_{\lambda_{\jmath}}+n_{j} ; j=1,2,3\right) .
\end{aligned}
$$

where,

$$
\begin{aligned}
& n_{\jmath}=\sum_{l} \tau_{\imath \jmath}, \quad \mu_{J}^{*}=\left(\sigma_{\mu_{j}}^{2} n_{\jmath} \bar{u}_{\jmath}+\rho_{j}^{2} \mu_{\mu_{j}}\right) /\left(\sigma_{\mu_{j}}^{2} n_{\jmath}+\rho_{j}^{2}\right), \quad \mathrm{SS}_{J}=\sum_{l} \tau_{\imath \jmath}\left(u_{\imath 0}-\bar{u}_{\jmath}\right)^{2}, \\
& \bar{u}_{j}=\left(1 / n_{j}\right) \sum_{l} \tau_{l j} u_{l 0}, \quad \rho_{j}^{* 2}=\left(\sigma_{\mu_{j}}^{2} \rho_{j}^{2}\right) /\left(n_{j} \sigma_{\mu_{j}}^{2}+\rho_{j}^{2}\right)
\end{aligned}
$$

In addition, the values $\rho_{J}^{2}$ are constrained to be no less than $\sigma^{2}$. If we simulate too low a value for a $\rho_{\jmath}$, we just keep repeating the simulation of $\theta$ until we satisfy the constraint.

Step 1 above is intractable as stated but would be easy if $\theta$ were known because

$\left(\tau_{\imath 1}, \tau_{12}, \tau_{\imath 3} \mid \theta, u_{0}\right) \sim$ Multinomial $\left(\lambda_{i 1}^{*}, \lambda_{i 2}^{*}, \lambda_{i 3}^{*} ; 1\right)$, for $i=1, \ldots, n$,

where

$$
\lambda_{i j}^{*} \propto \lambda_{J} \frac{1}{\rho_{J}} \phi\left(\frac{u_{J}-\mu_{j}}{\rho_{J}}\right), \quad \text { for each } i, j,
$$

and $\phi$ is the standard Normal density function. In our application of the data augmentation algorithm, we simulate a single random sample $\theta^{*}$ from $P\left(\theta \mid u_{0}\right)$, as follows:

1. Choose a reasonable starting point for $\theta^{*}$. We use the posterior maximum of $P\left(\theta \mid u_{0}\right)$, which we estimate by the EM algorithm (Dempster et al. 1977), again treating $\tau$ as unobserved data.

2. Repeat the following steps a number of times:

(a) Sample $\tau^{*}$ from $P\left(\tau \mid \theta=\theta^{*}, u_{0}\right)$

(b) Sample $\theta^{*}$ from $P\left(\theta \mid \tau=\tau^{*}, u_{0}\right)$

For our data, the distribution of simulated values $\theta^{*}$ appears to converge after 10 iterations. 


\section{Averaging over Uncertainty in $\gamma$}

We can factor the conditional posterior density as follows:

$$
\begin{aligned}
P\left(\gamma \mid \theta, u_{0}\right) & =\prod_{i} P\left(\gamma_{1} \mid \theta, u_{i 0}\right) \\
& \propto \prod_{l} P\left(u_{t 0} \mid \gamma_{1}, \theta\right) P\left(\gamma_{1} \mid \theta\right)
\end{aligned}
$$

The first factor here is just the Normal error density from the model (6), and the second factor is the Normal-mixture density parameterized by $\theta$. Their product yields a new Normal-mixture density with easily calculated parameters $\tilde{\theta}_{t}$ for each district; we sample from these independent distributions.

For each uncontested district, we simulate $\gamma_{t}$ from the truncated Normal distribution, equation (5). We combine these with the simulated values $\gamma_{t}$ for contested districts to get a sample vector $\gamma$ from its posterior distribution.

Averaging over $u_{t}$

To estimate the seats-votes curve and its variability, we first approximate the first two moments of the joint conditional distribution $P\left(V_{t}, S_{t} \mid \gamma, \delta_{t}\right)$ for several values of $\delta_{t}$.

The aggregate votes and seats are averages of their district-level counterparts $v_{u}$ and $s_{u}$, which in turn depend on $\gamma_{t}$ and $\delta_{t}$ only through their mean $\alpha_{u}=\gamma_{t}+\delta_{t}$. Thus, the desired conditional moments can be expressed in terms of the following expectations:

$$
\begin{aligned}
E\left(v_{u} \mid \alpha_{u}\right) & =\int_{-\infty}^{\infty} \frac{e^{u}}{1+e^{u}} \frac{1}{\sigma} \phi\left(\frac{u-\alpha_{u}}{\sigma}\right) d u, \\
E\left(s_{u} \mid \alpha_{u}\right) & =\int_{0}^{\infty} \frac{1}{\sigma} \phi\left(\frac{u-\alpha_{u}}{\sigma}\right) d u, \\
& =\Phi\left(\frac{\alpha_{u t}}{\sigma}\right), \\
\operatorname{Var}\left(v_{u} \mid \alpha_{u}\right) & =\int_{-\infty}^{\infty}\left(\frac{e^{u}}{1+e^{u}}\right)^{2} \frac{1}{\sigma} \phi\left(\frac{u-\alpha_{u}}{\sigma}\right) d u-\left[E\left(v_{u} \mid \alpha_{u t}\right)\right]^{2}, \\
\operatorname{Var}\left(s_{u t} \mid \alpha_{u t}\right) & =E\left(s_{u} \mid \alpha_{u}\right)\left[1-E\left(s_{u} \mid \alpha_{u}\right)\right], \\
\operatorname{Cov}\left(v_{u}, s_{u} \mid \alpha_{u t}\right) & =\int_{0}^{\infty} \frac{e^{u}}{1+e^{u}} \frac{1}{\sigma} \phi\left(\frac{u-\alpha_{u}}{\sigma}\right) d u-E\left(s_{u} \mid \alpha_{u t}\right) E\left(V_{u} \mid \alpha_{u t}\right) .
\end{aligned}
$$

Some of the above integrals are immediately evaluated through the standard Normal distribution function $\Phi$; we calculate the rest by approximating the inverse logit function $e^{u /}\left(1+e^{u}\right)$ by a third-degree polynomial in $u$.

We now approximate the seats-votes curve $E\left(S_{t} \mid V_{t}, \gamma\right)$ by the function $S(V)$ (given $\gamma$ ), defined by $E\left(S_{t} \mid \alpha_{t}\right)$ versus $E\left(V_{t} \mid \alpha_{t}\right)$, implicitly parametrized by $\alpha_{t}$ (or, equivalently, by the scalar $\delta_{t}$ ). Similarly, we approximate the variance as follows:

$$
\operatorname{Var}\left(S_{t} \mid V_{t}\right) \approx \operatorname{Var}\left(S_{t} \mid \alpha_{t}\right)-\frac{\operatorname{Cov}\left(V_{t}, S_{t} \mid \alpha_{t}\right)}{\operatorname{Var}\left(V_{t} \mid \alpha_{t}\right)}
$$

This variance depends on $V_{t}$ and is parameterized by $\delta_{t}$ in the above expression. The formula would be exactly correct if $S_{t}$ and $V_{t}$ were jointly Normally distributed and is a reasonable approximation for our problem. 


\section{Calculating Summaries}

Finally, we simulate several vectors $\gamma$ from the posterior density $P\left(\gamma \mid u_{0}\right)$. Each of these samples determines an electoral system for which we approximate the seats-votes curve and its variance as described above. From the seats-votes curve, we calculate the bias and responsiveness of the system between $45 \%$ and $55 \%$ (equation (12)). Finally, we estimate the bias and responsiveness of the true electoral system, and our uncertainty in these quantities, with the sample mean and variance of these values, over the many independent samples of $\gamma$.

We estimate the seats-votes curves and corresponding summaries of bias and responsiveness twice: once based on effective votes and once for underlying partisan predispositions. We do this by first letting $\gamma_{t}=\eta_{t}+\psi I_{t}$. When estimating the seats-votes curve for effective votes (i.e., ignoring the incumbency effect), we use $\gamma_{i}$ as in the above description. When we model underlying partisan predispositions, we use $\eta_{t}$ in place of $\gamma_{t}$ in the above procedures and then set $I_{i}=0$ for all districts (as if none of the incumbents run).

\section{REFERENCES}

Alford, John R., and David W. Brady. 1988. "Partisan and Incumbent Advantage in U.S. House Elections, 1846-1986." Working Paper 11, Rice University.

Alford, John R., and John R. Hibbing. 1981. "Increased Incumbency Advantage in the House." Journal of Politics 43: 1042-61.

Ansolabehere. Stephen, David Brady, and Morris Fiorina. 1988. "The Marginals Never Vanished?" Technical Report, Stanford University.

Backstrom, Charles, Leonard Robins, and Scott Eller. 1978. "Issues in Gerrymandering: An Exploratory Measure of Partisan Gerrymandering Applied to Minnesota." Minnesota Law Review $62: 1121-59$.

Bandemer v. Davis. 1984. 603 F. Supp. 1479, S.D. Ind.

Bauer, Monica, and John R. Hibbing. 1989. "Which Incumbents Lose in House Elections: A Response to Jacobson's 'The Marginals Never Vanished." ' American Journal of Political Science $33: 262-71$.

Born, Richard. 1979. "Generational Replacement and the Growth of Incumbent Reelection in the U.S. House." American Political Science Review 73:811-17.

Brady, David W. 1988. Critical Elections and Congressional Policy Making. Stanford: Stanford University Press.

Butler, David E. 1951. Appendix. In The British General Election of 1950, ed. H. G. Nicholas. London: Macmillan.

Cain, Bruce. 1984. The Reapportionment Puzzle. Berkeley: University of California Press.

Cain, Bruce, John Ferejohn, and Morris Fiorina. 1987. The Personal Vote: Constituency Service and Electoral Independence. Cambridge: Harvard University Press.

Collie, Melissa P. 1981. "Incumbency, Electoral Safety, and Turnover in the House of Representatives, 1952-1976." American Political Science Review 75:119-31.

Cover, Albert D., and David R. Mayhew. 1977. "Congressional Dynamics and the Decline of Competitive Congressional Elections." In Congress Reconsidered, ed. Lawrence C. Dodd and Bruce I. Oppenheimer. New York: Praeger.

Davis v. Bandemer. 1986. 106 U.S. Supreme Court 2797.

Dempster, Arthur P., Nan M. Laird, and Donald B. Rubin. 1977. "Maximum Likelihood from Incomplete Data via the EM Algorithm." Journal of the Royal Statistical Society Ser. B, 39: $1-38$.

Erikson, Robert S. 1971. "The Advantage of Incumbency in Congressional Elections." Polity $3: 395-405$. 
1972. "Malapportionment, Gerrymandering, and Party Fortunes in Congressional Elections." American Political Science Review 66:1234-55.

Ferejohn, John A. 1977. "On the Decline of Competition in Congressional Elections." American Political Science Review 28: 127-46.

Fiorina, Morris. 1977. Congress: Keystone of the Washington Establishment. New Haven: Yale University Press.

Garand, James C., and Donald A. Gross. 1984. "Change in the Vote Margins for Congressional Candidates: A Specification of the Historical Trends." American Political Science Review $78: 17-30$.

Gelman, Andrew, and Gary King. 1990a. "Estimating the Electoral Consequences of Legislative Redistricting." Journal of the American Statistical Association 85, 410:274-82.

. 1990b. "Estimating Incumbency Advantage without Bias." American Journal of Political Science forthcoming.

Gudgin, G., and P. J. Taylor. Seats, Votes, and the Spatial Organisation of Elections. London: Pion.

Hinckley, Barbara. 1981. Congressional Elections. Washington, DC: Congressional Quarterly Press.

Jacobson, Gary C. 1987. "The Marginals Never Vanished: Incumbency and Competition in Elections to the U.S. House of Representatives." American Journal of Political Science $31: 126-41$.

Kendall, M. G., and A. Stuart. 1950. "The Law of the Cubic Proportion in Election Results." British Journal of Sociology $1: 193-96$.

King, Gary. 1991. "Stochastic Variation: A Comment on Lewis-Beck and Skalaban's 'The RSquared'," Political Analysis, forthcoming.

- 1989a. Unifying Political Methodology: The Likelihood Theory of Statistical Inference. New York: Cambridge University Press. - 1989b. "Representation through Legislative Redistricting: A Stochastic Model." American Journal of Political Science 33: 787-824.

King, Gary, and Robert X. Browning. 1987. "Democratic Representation and Partisan Bias in Congressional Elections." American Political Science Review 81 : 1251-76.

Krehbiel, Keith, and John R. Wright. 1983. "The Incumbency Effect in Congressional Elections: A Test of Two Explanations." American Journal of Political Science 27: 140-57.

Mann, Thomas E., and Raymond E. Wolfinger. 1980. "Candidates and Parties in Congressional Elections." American Political Science Review 74:617-32.

Mayhew, David R. 1971. "Congressional Representation: Theory and Practice in Drawing the Districts." In Reapportionment in the 1970s, ed. Nelson W. Polsby. Berkeley: University of California Press.

- 1974. "Congressional Elections: The Case of the Vanishing Marginals." Polity 6:295-317.

Niemi, Richard G., and John Deegan, Jr. 1978. "A Theory of Political Districting." American Political Science Review 72:1304-23.

Niemi, Richard G., and Patrick Fett. 1986. "The Swing Ratio: An Explanation and an Assessment." Legislative Studies Quarterly 11:75-90.

Morgan, Bryon. 1984. Elements of Simulation. London: Chapman and Hall.

Nelson, Candice. 1978-79. "The Effects of Incumbency on Voting in Congressional Elections." Political Science Quarterly 93:665-78.

Owen, Guillermo, and Bernard Grofman. 1988. “Optimal Partisan Gerrymandering.” Political Geography Quarterly 7.1:5-22.

Payne, James L. 1980. "The Personal Electoral Advantage of House Incumbents." American Politics Quarterly 8:375-98.

Peters, John G., and Susan Welch. 1980. "The Effects of Charges of Corruption on Voting Behavior in Congressional Elections." American Political Science Review 74:697-708.

Quandt, Richard E. 1974. "A Stochastic Model of Elections in Two-Party Systems." Journal of the American Statistical Association 69:315-24. 
Rubin, Donald. 1974. "Estimating Causal Effects of Treatments in Randomized and Non-Randomized Studies." Journal of Educational Statistics 66:688-701.

Schrodt, Philip A. 1981. "A Statistical Study of the Cube Law in Five Electoral Systems.” Political Methodology 7:31-53.

Silverman, B. W. 1986. Density Estimation for Statistics and Data Analysis. London: Chapman and Hall.

Tanner, Martin A., and Wing H. Wong. 1987. "The Calculation of Posterior Distributions by Data Augmentation." Journal of the American Statistical Association 82:528-50.

Tufte, Edward R. 1973. "The Relationship between Seats and Votes in Two-Party Systems." American Political Science Review 67:540-54.

1974a. "Communication." American Political Science Review 68:207-13.

1974b. Data Analysis for Politics and Policy. Englewood Cliffs, NJ: Prentice-Hall. 